\title{
Racism in Clinical Psychology within the Heart of the Old Empire
}

\author{
Nicholas Wood; Visiting Lecturer, UEL
}

It has taken the worldwide protests in June, against the brutal murder of George Floyd, to finally persuade the British Psychological Society (BPS) to admit its own house is not in order, regarding racism within UK psychology (Bajwa, 2020; Division of Clinical Psychology, 2020). It had also taken several events within the past year to drive home how perniciously racism is operating within the profession locally.

The ability of psychologists to both recognise and appropriately address racism within the profession (as well as client work) has long been a sensitive (and often silenced) issue (Howitt \& Owusu-Bempah, 1994). As a direct result of sustained critique and demands by the 'Race' and Culture Faculty since 1991, the wording of core competencies required of clinical psychologists was finally changed:

. . the clinical psychologist will be aware of the importance of diversity, the social and cultural context of their work. . . and have the skills, knowledge and values to work effectively with clients from a diverse range of backgrounds, understanding and respecting the impact of difference and diversity upon their lives. (BPS, 2019, pp. 6-8) 
However, there has also been a significant rise in stigma, prejudice and racism following the Brexit vote, and the impact of the Covid-19 pandemic has highlighted the painful structural inequalities faced by Black and 'Minority Ethnic' ('BME') people, all with considerable physical and negative mental health costs (Bhui, 2016; Minhas, 2019; University College London, 2020). Clinical psychology needs to take an active stance to address this issue - and we should thus be looking for ways not just to foster inclusion and equality but to develop anti-racism awareness and practices too - as well as ensuring trainers (and supervisors of those in training) are competent in addressing racism and issues of culture in supervision (Patel, 2011; Wood \& Patel, 2019).

The profession of clinical psychology in the United Kingdom has responded to the challenges posed by the Equality Act and the alarmingly consistent statistics which betray, decade after decade, a systematic and disproportionate predominance of clinical psychology trainees who are White, despite increased 'diversity' access initiatives, such as the DCP-London 'BME' mentoring scheme (Scior, Williams \& King, 2015). More recently, members of the Division of Clinical Psychology Minorities Group (DCP MG) have been tackling this issue, with creativity and determination (Rhodes, 2020). 
A problematic assumption that may underlie some of these 'diversity and access initiatives', however, is that 'Black and minority ethnic' people are 'not attracted' to the profession and that if we are able to get more of 'them' into training programmes and the profession, then we can counter charges of discrimination and Eurocentricity in psychology. A related assumption is that the mere presence of trainees from Black and minority ethnic backgrounds can eradicate Whiteness and racism in the profession and contribute to learning by trainers and trainees about 'diversity' or, more specifically, neutralise criticisms of the profession as being exclusive, predominantly White, Eurocentric and discriminatory (Wood \& Patel, 2017).

The limitations of diversity agendas, without the wider addressing of sociopolitical structures and systemic and institutional racism within the profession, are significant (Daiches, 2010). The painful persistence of hearing about racist experiences from trainees within the profession, was a reason for Nimisha Patel to suggest a special issue of the Clinical Psychology Forum (v323, 2019), focusing specifically on racism within training.

The month this special issue was launched, the Group of Trainers in Clinical Psychology held their annual conference. There was a concerted effort by the hosts (Liverpool) to focus on the theme of social justice and the responsibility of the profession. Unfortunately, however, one of the items that was rolled out towards the end of dinner was a purportedly 'well meant' - but 
with little apparent consideration of Black trauma/pain - re-enactment of a 'slave auction', done without due framing or context/support being provided (Association of Clinical Psychologists, 2019). This resulted in serious psychological distress from Black participants (Patel et al., 2019). There was a failure to both recognise and address this at the time - a case of ongoing 'Whiteness' in operation. Post-conference apologies were eventually issued, but only after a prolonged period of 'white silence'. (Letters from 'both sides' were eventually posted in the Clinical Psychology Forum, February 2020.)

Following this specific debacle, it was agreed that at the Division of Clinical Psychology annual Conference in January 2020, the issue of racism and distress from the GTiCP Conference would be addressed. This was indeed timetabled and went ahead. However, during a poster session an attendee whose topic was on supporting African and Caribbean men transition from forensic services to the community - found her poster had been graffitied with ‘Keep BME out of services' (Sham Ku \& Mia, 2020).

More recently, The Psychologist has published several letters - mainly from seemingly White members of the profession - attacking the 'increasing left wing bias', of a perceived 'social justice' agenda within the BPS. The latest letter titled, 'Why I No Longer Wish to Be Associated With the BPS', was withdrawn after it was apparent how much distress/harm it was causing, effectively dismissing racism (and its more covert cousin, micro-aggressions) 
as an 'unscientific' notion. (Responses to the letter, including my own, have been kept available online: Sutton, 2020.)

It is thus clear there are members of the BPS who do not wish to welcome 'diversity' - and so, unless we can find a way to fully engage the dominant White membership of the society with a genuine and deep-seated commitment to not only want 'diversity', but to examine (and challenge) their own (and others) positions within privileged White structures, attempts to make headway will be nothing more than saying the right words (performative whiteness). Racism has a long and tenacious history of transmogrifying, or even hiding in plain sight, as and when it needs to (Fernando, 2017; Steyn \& Foster, 2008).

How then do we attempt to do make the changes the profession requires? The BPS has begun a 'Diversity and Inclusion Taskforce' headed by Nasreen Fazal-Short (2020), aimed at developing a 5-year strategy and 'broadening the conversation to institutional bias'. The central aim of this should be the embedding of anti-racism as a core value and competency within the profession, codified by the Health and Care Professions Council (Barwick, 2020). That means teaching and training is key - Nimisha Patel and I are gathering a 'whiteness' set of resources to this end, enriched by interviewing over 100 UK clinical psychology trainers, trainees and service users. Crossnational learning (e.g., with South Africa) could be hugely beneficial too. 
However, in a country still recently insisting on singing Britons never, never, never will be slaves, this will be no straight-forward matter. Still, Black Lives Matter and the Colston slaver statue was toppled (Harker, 2020). History lives.

\section{References}

Association of Clinical Psychologists. (2019). Racism in the Profession of Clinical Psychology. See weblink.

Bajwa, S. (2020). Is the British Psychological Society institutionally racist? BPS Blog (Chief Executive, 1st July.). See weblink

Barwick, J. (2020, June 8). Black lives matter. Health and Care Professions

\section{Council. See weblink.}

Bhui, K. (2016). Brexit, social division and discrimination: Impacts on mortality and mental illness? The British Journal of Psychiatry, 209(2), 181-182. http://dx.doi.org/10.1192/bjp.209.2.181

British Psychological Society. (2019). Standards for the accreditation of Doctoral programmes in clinical psychology.

Daiches, A. (2010). Clinical psychology and diversity: Progress and continuing challenges: A commentary. Psychology, Learning and Teaching, 9(2), 28-29.

Division of Clinical Psychology. (2020, June). Black Lives Matter; George Floyd's Life Matters: Statement by the DCP Representative Assembly. https://www.bps.org.uk/member-microsites/division-clinicalpsychology/news 
Fazal-Short, N. (2020). We need to broaden the conversation to institutional bias. The Psychologist, 33, 22-24.

Fernando, S. (2017). Institutional racism in psychiatry and clinical psychology. Palgrave Macmillan.

Harker, J. (2020, September 2). The Rule, Britannia! Row is too important for anti-racists to ignore. The Guardian. See weblink

Howitt, D., \& Owusu-Bempah, J. (1994). The racism of psychology: Time for change. Prentice-Hall.

Minhas, P. (2019). Racism rising since BREXIT vote. Opinium. See weblink Patel, N. (2011). Power and difference in clinical psychology supervision: The case of 'race' and culture. In I. Fleming \& L. Steen (Eds.), Supervision and clinical psychology: Theory, practice and perspectives (2nd ed., 96-117). Brunner-Routledge.

Patel, N., Alcock, K., Alexander, L., Baah, J., Butler, C., Danquah, V., . . . Wood, N. (2019). Racism is not entertainment. Psychologists for Social Change. http://www.psychchange.org/racism-is-not- entertainment.html Rhodes, E. (2020, September 14-16). Systematic disadvantage can accumulate and prevent access to the profession. The Psychologist, 14-16. https://thepsychologist.bps.org.uk/volume-33/september-2020/ systematic-disadvantage-can-accumulate-and-prevent-access-profession Scior, K., Williams, J., \& King, J. (2015). Is access to clinical psychology 
training in the UK fair? Clinical Psychology Forum, 274, 12-18.

Sham Ku, K., \& Mia, A. (2020). A culture of silence and denial. The Psychologist, 33, 2-3.

Steyn, M., \& Foster, D. (2008). Repertoires for talking White: Resistant whiteness in post-apartheid South Africa. Ethnic and Racial Studies, $31(1), 25-51$.

Sutton, J. (2020). Why I no longer wish to be associated with the BPS. The Psychologist, Debates. See weblink

University College London. (2020). Levels of depression and anxiety higher amongst those from BAME backgrounds during lockdown. UCL News.

\section{See weblink}

Wood, N., \& Patel, N. (2017). On addressing 'Whiteness' during clinical psychology training. South African Journal of Psychology, 47(3), 280291. https://doi.org/10.1177/0081246317722099

Wood, N., \& Patel, N. (Eds.). (2019, November). Racism. Special Issue, Clinical Psychology Forum no 323. 